\title{
AS FACETAS DA CRÍTICA À ARTE MODERNA NO EIXO RIO-SÃO PAULO
}

\section{THE FACETS OF MODERN ART CRITICISM IN RIO-SÃO PAULO AREA}

\author{
Andressa de Oliveira Nascimento ${ }^{1}$
}

Resumo: Os modernistas foram muito efetivos ao diminuírem as tensões críticas que acompanharam todo seu processo de afirmação nos Estados do Rio de Janeiro e São Paulo. Muito frequentemente as críticas à arte moderna têm sido resumidas sob a oposição "academicismo-modernismo", o que supõe uma contradição entre tradição e modernidade que surge da narrativa histórica modernista. Contudo, os matizes que permeavam as críticas anti-modernistas são muito mais variados e duram muito mais tempo, englobando desde conceitos dos ideais cientificistas e evolucionistas do século XIX até termos políticos no século XX. Assim, o presente artigo busca analisar algumas críticas ao Modernismo e a seus intérpretes nas artes visuais, tais como Monteiro Lobato, Oswaldo Teixeira, Newton Amarante, Augusto Bracet e Oscar Guanabarino.

Palavras-chave: Crítica da arte; Anti-modernismo; Modernismo.

Abstract: The modernists were very effective in reducing the critical tensions that accompany their entire affirmation process in the States of Rio de Janeiro and São Paulo. Modern Art Criticism has very often been summed up under this "academicism-modernism" opposition, which supposed a contradiction between tradition and modernity that arises from the modernist historical narrative. However, the nuances that permeated anti-modernist criticism are much more varied and last much longer. It encompasses concepts from the scientism and evolutionary theory of the

\footnotetext{
${ }^{1}$ Graduanda em História (Licenciatura e Bacharelado) pela Universidade Federal do Paraná (UFPR). Email para contato: andressa.oliveiranasc@gmail.com. Endereço para o Currículo Lattes: http://lattes.cnpq.br/2192317753265674.
} 
19th century until the adoption of political terms in the 20th century. Thus, this article seeks to analyze some criticisms of modernism and its interpreters, such as Monteiro Lobato, Oswaldo Teixeira, Newton Amarante, Augusto Bracet and Oscar Guanabarino.

Keywords: Art criticism; Anti-modernism; Modernism.

\section{Introdução}

Durante muito tempo o anti-academicismo foi responsável pela falta de interesse de pesquisadores em entender a produção artística brasileira do final do século XIX e início do XX. Esse período seria definido, em especial pelos estudos baseados nas narrativas modernistas, como uma extensão da arte acadêmica produzida pela Academia Imperial de Belas Artes (AIBA). ${ }^{2}$ Assim sendo, o Modernismo surgiria como um "herói" que salva a arte brasileira da estagnação em que se encontrava. Ou seja, alheia a todos os avanços da arte pelo mundo, os ideais estéticos das academias teriam permanecido intocados pela modernidade e a ruptura com a tradição viria apenas em 1917, com a exposição de Anita Malfatti, e em 1922, com a Semana da Arte Moderna em São Paulo. A partir daí, além de recolocar a arte brasileira a par dos avanços artísticos internacionais, o Modernismo teria também reintroduzido aspectos próprios da cultura brasileira no mundo artístico. Longe de afirmar essa perspectiva, pretende-se mostrar

2 O termo "arte acadêmica" busca englobar a produção artística brasileira desenvolvida pela Academia Imperial de Belas Artes (1826) até a Escola Nacional de Belas Artes (1890). Assim, essa generalização esconde, por exemplo, as tentativas dos artistas brasileiros de se modernizarem (em seus termos, não aqueles impostos pelo modernismo) e "esconde a ignorância de muitos sobre a riqueza da arte desse período no Brasil" (CHIARELLI, 2010: 120). 
que ela foi efetiva ao diminuir as tensões críticas que acompanham todo o processo de afirmação do Modernismo nos Estados do Rio de Janeiro e São Paulo. O mito fundador do Modernismo cria um inimigo ao qual se opõe, qual seja, a arte acadêmica e as instituições artísticas.

É lógico supor, dentro desse cenário, que as críticas direcionadas à arte moderna no Brasil também eram fruto desse "academicismo". E de fato isso é parte da realidade, uma vez que como membros de uma instituição tida como paradigma da arte nacional, os acadêmicos da Escola Nacional de Belas Artes (ENBA) não eram adeptos a mudanças bruscas da tradição. No entanto, isso não implica aceitar a narrativa modernista de que eles estavam passivos à modernidade. Pelo contrário, adentravam em seus próprios moldes a modernidade enquanto recusavam a noção de modernidade divulgada pelos modernistas. Assim, as críticas às propostas modernistas possuem mais facetas do que são possíveis reunir sobre a oposição Modernismo-academicismo.

Como característica da auto-imagem que o Modernismo forja para si mesmo, "modernidade", "arte moderna", "vanguarda" e "Modernismo" são definidos como um só e associados exclusivamente ao seu movimento (e a alguns pintores que seriam retomados pelos modernistas como genealogia das práticas do presente, tal como Almeida Júnior) (FABRIS, 2003) . Ao que parece, a modernidade de fins do século XIX e início do XX - a valorização do entorno local brasileiro a partir do realismo e do naturalismo - não tinha quaisquer conexões com a modernidade pretendida pelos modernistas. Portanto, o modernismo surgiu, segundo os discursos criados 
pelos proponentes desse movimento, como marco da arte contemporânea brasileira e seria o responsável por ter revivido e "reabrasileirado" aspectos da arte colonial brasileira, sufocadas pelo "academicismo e impressionismo anafados" (ANDRADE apud CHIARELLI, 2010: 126). Mas como aponta Chiarelli, de fato deveriam haver semelhanças entre as produções Modernistas e a modernidade pretendida pelos pintores acadêmicos da ENBA:

Se muitos aspectos mudam — sobretudo aqueles de caráter estético - é possível pensar que várias questões de fundo se mantêm dentro de uma duração que não se mede, nem por movimentos que teoricamente se opõem (2010: 131).

Recuando um pouco no tempo até as décadas de 1870 a 1890 temos o início da inserção na crítica artística brasileira do cientificismo, evolucionismo e degeneracionismo. No Brasil, o pensamento degeneracionista enxergava a origem da degeneração no passado atrelado à escravidão e à monarquia. Assim, a renovação da sociedade estava voltada para um futuro possível. Nas artes isso se traduz em críticas à AIBA apegada ao academicismo clássico ${ }^{3}$ e na busca por uma nova estética ajustada à modernidade. Essa busca partia da crença de que era possível

${ }^{3}$ Deve-se notar aqui que quando os renovadores das décadas de 1870 a 1890 utilizam o termo "academicismo" eles se referiam à estética neoclássica, em especial à idealização dos corpos e à mimese dos clássicos que exclui a individualidade dos pintores. Defendiam, assim, o realismo e o naturalismo. O uso do termo "academicismo" para designar a arte da Escola que adentra o século XX é fruto da narrativa modernista. 
estudar a estética da arte através da ciência moderna. Nomeada de "fisiologia da estética" - por um redator chamado "Fromentin", na Revista Musical e de Bellas Artes, em 1879 -, o estudo da estética artística acreditava ser possível estabelecer leis que regiam o funcionamento do prazer estético por meio dos componentes que formavam a sensação: sua intensidade, sua variedade e a concordância de vibrações (CAIRES, 2019: 76). Deste modo, a arte deveria ser dotada de liberdade de expressão tornando possível aos artistas colocarem a si mesmos e suas personalidades em suas pinturas, fugindo da cópia dos clássicos. Travava-se então "a primeira luta pela modernidade no Brasil", cujo resultado é a Reforma de 1890 da AIBA, formando, com isso, a ENBA (CAIRES, 2019: 74).

Adentrando o século XX, com a chegada das vanguardas ao Brasil, essa crítica cientificista abandona a modernidade e se volta à tradição. As associações entre a cultura popular (vista como inferior) e o "primitivismo" levam a afirmação de que a arte modernista provocaria a degeneração da arte brasileira. Relacionada à inferioridade intelectual e cultural, a "arte primitiva" recebia alcunhas de "infantil" e "monstruosa" e, portanto, ao reivindicar a cultura popular e ao produzir uma arte que deixa de lado a forma, o Modernismo acarretaria o retorno da arte brasileira a uma "arte primitiva". Daí que eram comuns as descrições em jornais e revistas da arte Modernista como sendo teratológica, uma obra de doidos e a causadora da decadência da arte brasileira. De modo geral, o conceito de "degeneração" pautava-se na crença de que existia na sociedade um perigo constante de retrocesso civilizacional. Assim, ao apontar a arte como "degeneração", 
esses críticos acreditavam que ela podia causar a perda das vantagens evolutivas e do progresso alcançados.

Gilda de Mello e Souza (apud CAIRES, 2019) apresenta duas categorias de classificação dos textos críticos das vanguardas: a primeira surgia devido a um evento pontual, como a reação de Monteiro Lobato à exposição de 1917 de Anita Malfatti, e se valiam de extrema violência verbal; a segunda tratava-se de uma crítica mais regular em jornais e revistas que permitia aos seus autores aprofundarem suas reflexões e opiniões sobre a Arte Modernista. Para Souza essa segunda crítica refletia, em geral, a opinião do senso comum e, assim sendo, permite observar o pensamento estético dominante que definia o que se desejava da arte. $\mathrm{O}$ Modernismo foi bem-sucedido em abafar essas tensões críticas existentes no período, resumindo-as, muitas vezes, à figura de Monteiro Lobato, quando, na verdade, a associação entre degeneração e arte moderna era comum tanto no Brasil quanto na Europa (CHIARELLI, 2010).

Se estendendo durante todo século XX, as críticas anti-modernistas e também os próprios modernistas - aderem a termos e ideias do cenário político e social internacional: a arte Modernista era o "bolchevismo nas artes" (GUANABARINO apud CAIRES, 2019: 91) enquanto os anti-modernos eram "o terceiro reich" nazista (SILVEIRA, 1942: 12). As associações dos modernistas ao comunismo, ou mesmo aos judeus, foi prática comum nesse meio, ${ }^{4}$ assim como também o foram ligações dos

${ }^{4}$ Com a implementação do Estado Novo e as aproximações de Vargas aos ideais nazistas, a polícia política tinha como um de seus objetivos vigiar e controlar os artistas de vanguardas e suas "ideias avançadas". Em 1941, a declaração de guerra 
Cadernos de Clio, Curitiba, v. 12, $\mathrm{n}^{\circ} .1,2021$

críticos à bastilha francesa e aos nazistas alemães (SILVEIRA, 1942).

\section{Os críticos do Modernismo brasileiro (eixo Rio-São Paulo, década de 1910 a 1950)}

Oscar Guanabarino (1851-1937), Monteiro Lobato (1882-1948), Augusto Bracet (1881-1960), Oswaldo Teixeira (1905-1974) e Newton Amarante (falecido em 1968) são apenas alguns dos nomes daqueles que produziram, durante o século $\mathrm{XX}$, críticas à arte modernista. ${ }^{5}$ Em resumo, acusavam a Arte Modernista ora de ter um programa político de desorganização social, ora de serem apenas enganadores e pseudo-artistas empenhados em fazer nome através de rabiscos e deformações.

O pianista e dramaturgo brasileiro Oscar Guanabarino é o caso mais particular: produziu críticas artísticas em periódicos que atravessam mais de 40 anos. De defensor da modernidade passa, no período final de sua produção, à defesa da tradição. Nas décadas de 1880 a 1900 Guanabarino expunha ideias renovadoras atacando "uma arte que, naqueles tempos [...] era, para ele, retrógrada" (GRANGEIA apud CAIRES, 2017: 89). O passado escravista e monárquico brasileiro deveria ser substituído, assim como as ideias clássicas propagadas no campo artístico, deixando de lado

dos Estados Unidos ao Eixo (Alemanha, Itália e Japão) torna essas ligações insustentáveis, fazendo com o governo Vargas comece a se aproximar da estética modernista, sinal claro de ideias anti-fascistas e progressistas (CAIRES, 2019: 185).

${ }^{5}$ Apenas para citar alguns outros nomes, Caires (2019) trabalha ainda com os críticos da arte moderna Alfredo Mário Guastini (1884-1949), Carlos Maul (1887-1973) e o juiz militar Raul Machado. 
“o virtuosismo, o acabamento impecável do desenho e o uso artificial do preto" (GRANGEIA apud CAIRES, 2017: 89). Enquanto Almeida Júnior (conhecido como o pintor dos “caipiras" brasileiros) e Henrique Bernardelli (que também expressava ideias renovadoras) ilustravam os novos caminhos que a arte deveria seguir, Vítor Meirelles e Pedro Américo, os grandes do império, representavam o passado que deveria ser superado. ${ }^{6} \mathrm{Em}$ fins do século XIX, suas críticas começam a se modificar. Caires aponta que já em 1897 Guanabarino começa a expressar um tom retrógrado através da crítica que faz à artista argentina Diana Cid. "É a maldita escola simbolista", escreve ele, que vem

invadindo o cérebro dos artistas, produzindo loucura [...] que ameaçaria arruinar a arte [...] o corpo humano não tem aquela forma duvidosa e esses velados são simples pretexto para evitar a dificuldade do desenho rigoroso (CAIRES, 2017: 87).

Nos anos 1920 essa crítica acentua seu caráter retrógrado. Em 1921, Guanabarino escreve:

As belas artes, como o mundo social e político, estão passando por uma crise que pode ser atribuída ao desencadeamento de uma loucura epidêmica; e assim como o bolchevismo da Rússia pretende invadir todos os países ocidentais da Europa, para depois levar à corrupção aos outros continentes, espalhando a vesânia para substituir a ordem, assim também

${ }^{6} \mathrm{O}$ pensamento renovador permeava a proposta de Reforma da AIBA em 1890. Liderados por Rodolpho Bernardelli e Rodolpho Amoedo, os alunos da Academia propuseram sua reforma, pois esta instituição ainda "mantinha vícios acumulados durante o longo período imperial” (CAIRES, 2017: 82). 
temos o bolchevismo nas artes, com a pretensão de destruir tudo quanto o gênio conquistou durante séculos e impor produções que destroem todas as leis estéticas e que atestam uma revolução desvairada, sem princípios fundamentais e sem orientação alguma, sendo essa a sua única lógica, que é a lógica dos desequilibrados (apud CAIRES, 2017: 91, grifos meus).

Responsável pela degradação da arte brasileira, do "gênio" artístico, o Modernismo é, pela visão do crítico, "uma loucura epidêmica" e "uma revolução desvairada". Assim, ele faz também uma associação à revolução bolchevique na Rússia: o Modernismo é o "bolchevismo na arte", uma revolução que acontece sem leis, sem fundamentos, acontece com o objetivo de destruir. Essa associação entre política e arte é bastante comum entre os críticos da arte Modernista, ela aparece em 1921 com Guanabarino e é reiterada mais tarde por Newton Amarante, em 1951. Essa noção de "revolução desvairada" aparece, inclusive, no texto de Monteiro Lobato a Anita Malfatti em 1917.

Uma das críticas à arte Modernista mais conhecidas é, definitivamente, o texto "Paranóia ou Mistificação?”, de Monteiro Lobato, publicado em 1917 em razão da exposição de Anita Malfatti. Para Lobato, a necessidade de produzir uma arte brasileira vê-se ligada ao incentivo de pintar o entorno local através do que sente o pintor. Definia-se assim o "naturalismo nacionalista" (CHIARELLI, 2010: 116). Essa arte deveria representar o seu entorno, mantendo-se fiel à reprodução da natureza, tal como nas obras de Almeida Júnior. O naturalismo nacionalista (ou 
regionalista) configurava então uma primeira proposta de produzir o "abrasileiramento" da arte e viria daí, então, os primeiros conflitos com o Modernismo, em especial pelo uso do discurso degeneracionista (CAIRES, 2019: 98).

O "pré-modernismo" surge na história para designar o período imediatamente anterior ao Modernismo, que serve de anteparo para as ideias que vão ser divulgadas mais atentamente e radicalmente pelos modernistas. Nessa narrativa, o naturalismo nacionalista de Lobato estabeleceria anterioridade, sendo definido pelo futuro e perdendo sentido próprio (COLI apud SIMIONE, STUMPF, 2014: 112). Chiarelli (2010) aponta que a narrativa modernista buscou apagar a existência de uma crítica renovadora anterior à sua própria, assim o termo "pré-modernista" implica no esquecimento de que existiam critérios culturais próprios do período de produção das obras (SIMIONE, STUMPF, 2014: 112). Enquanto os artistas do império eram os "acadêmicos" e a geração posterior a década de 1920 "modernos", os artistas da Primeira República não possuíam uma designação capaz de agrupá-los e foram, assim, empurrados pela narrativa modernista para noção de "academicistas".

Caracterizado pela posteridade como "pré-modernista", Monteiro Lobato foi um ferrenho crítico da estética modernista. Em sua crítica a Malfatti escreve que "todas as artes são regidas por princípios imutáveis, leis fundamentais" (1917: 1) o que impossibilita que o artista se afaste das formas da natureza como percebidas por seus sentidos. Volta-se, então, à crítica cientificista produzida em fins do século XIX. Assim, a arte que 
nasce da deformação é um "produto lógico dos cérebros transtornados pelas mais estranhas psicoses" (LOBATO, 1917: 1), interessando apenas aos psicólogos e não ao público em geral. Deste modo, na crítica à exposição de Malfatti, Lobato divide os artistas de duas formas: aqueles que "vêem normalmente as coisas e em consequência disso fazem arte pura" e aqueles que "vêem anormalmente a natureza, e interpretam-na à luz de teorias efêmeras, sob a sugestão estrábica de escolas rebeldes, surgidas cá e lá como furúnculos da cultura excessiva" (LOBATO, 1917: 1). A noção de “cultura excessiva" remete aos ideais degeneracionistas do século XIX segundo os quais o acúmulo de civilização - e cultura - levaria à barbárie, à decadência, à degeneração e, ainda, à "revolução desvairada" de Guanabarino (CAIRES, 2019: 103). Assim, para Lobato a arte modernista nada mais era do que a exemplificação desse quadro, fruto do "cansaço e do sadismo de todos os períodos de decadência" e sinal claro de loucura (LOBATO, 1917: 1). Lobato continua:

Enquanto a percepção sensorial se fizer anormalmente no homem, através da porta comum dos cinco sentidos, um artista diante de um gato não poderá "sentir" senão um gato, e é falsa a "interpretação" que o bichano fizer um "totó", um escaravelho ou um amontoado de cubos transparentes. Estas considerações são provocadas pela exposição da Sra. Malfatti, onde se notam acentuadíssimas tendências para uma atitude estética forçada no sentido das extravagâncias de Picasso e companhia (1917: 1). 
Essa percepção anormal da realidade nada mais faria além de desnortear o público, aproveitando-se de sua ingenuidade para tornar aceitável uma arte "anormal e teratológica" que nasce da "paranóia e mistificação" (LOBATO, 1917: 1). Seriam os modernistas, assim, charlatões que tentam iludir o público com farsas em forma de pintura.

Augusto Bracet faz eco de algumas críticas de Lobato. Bracet, no entanto, não é uma figura muito conhecida. Apesar de ter sido professor, de 1926 a 1951, e até mesmo diretor da ENBA, entre 1938 e 1948, seu nome parece ter sido apagado da história da arte brasileira. Aparece em alguns trabalhos sobre a ENBA, mas apenas para mencionar por cima o acontecido na exposição anual de Belas Artes de 1942. No Salão de 1942, Bracet teria vetado a exposição de algumas obras modernistas que, segundo ele, se afastavam dos ideais estéticos da academia, dentre elas uma estátua e um painel de Alfredo Ceschiatti. Nesse cenário, os acadêmicos eram os "velhinhos" em oposição à nova geração (os modernistas), que era uma "classe unida, com consciência, com vontade de aprender" (SILVEIRA, 1942). Assim, alguns alunos modernistas montaram uma exposição na Associação Brasileira de Imprensa cujo título era: "Os dissidentes", liderados por Maurício Roberto, Percy Deane e José Moraes.

O poeta modernista, Murilo Monteiro Mendes, em razão da exposição, diz aos alunos dissidentes: "vocês acabaram de praticar um ato decisivo: começaram o ataque à Bastilha das belas-artes, onde se refugiou o convencionalismo" (TRIUNFO, 1943: 33). O jornalista Joel Silveira (1942: 
13) faz eco de Mendes e acrescenta "aquilo lá [a ENBA] é um terceiro reich" e finaliza:

talvez isso não fique bem a um repórter, cidadão essencialmente informativo. Mas quem quiser que ache ruim. Torço pelos rapazes rebelados e faço meu grito o grito de Chico Barbosa: - Morra o Professor Bracet!

Em entrevista concedida a João Angyone Costa (1927), Bracet afirma que a arte é expressão da individualidade dos artistas, por isso se coloca contra a influência das escolas artísticas que seriam a negação da liberdade artística. Mas aqui também, como com Lobato e Oswaldo Teixeira, essa liberdade está intimamente atrelada à manutenção da forma $\mathrm{e}$ do desenho. Esse pensamento se repete em entrevista a Tapajos Gomes, em 1942, quando Bracet afirma que para a arte modernista

O desenho não é mais necessário. Ser guiado por um mestre é errado, pois que o artista nada tem que aprender. Tudo é espontaneo. E assim todos são artistas. Qualquer rabisco, qualquer borrão, sem fórma, sem proporção, sem harmonia de cores, sem perspectiva, nem linear nem aérea, classificam de "arte moderna" ou "modernista". É por isso que, em algumas exposições, encontramos tantas monstruosidades, conjuntos de elementos desconexos, puramente literários, que, para serem compreendidos, exigem longas explicações... Em alguns, isso é o resultado da falta de preparo. Em outros, o medo de não serem considerados modernos. (apud GOMES, 1942: 1, grifos meus) 
A verdadeira arte moderna, nas palavras do pintor, surgia através da representação sincera da natureza por meio da "simplicidade, solidez [e] luz”, mas, frisa ele, sem deturpações (GOMES, 1942).

Figura próxima a Bracet, Oswaldo Teixeira foi diretor do Museu Nacional de Belas Artes de 1937 a 1961. Tinha, portanto, poder de vetar obras modernistas por vias oficiais como diretor do Museu. Teixeira foi muito mais enfático em suas críticas ao Modernismo que Bracet e, por isso, é uma figura muito mais conhecida e polêmica. "O maior inimigo do modernismo no Brasil", é desta forma que Oswaldo Teixeira é apresentado por Jayme Maurício (1973: 10), em 1973, em texto de homenagem aos 50 anos do Modernismo (realizados em 1972 e tendo como marco do Modernismo, claramente, a Semana da Arte Moderna de 1922). Segue a apresentação que o jornalista faz de Teixeira:

O Sr. Oswaldo Teixeira já é bem conhecido por seus ataques ao Modernismo, por sua pintura submissa à tarefa de má reprodução de grandes artistas do século passado; por sua pintura sem invenção e sem personalidade incapaz de se aproximar do século XIX (MAURÍCIO, 1973: 10).

Sua direção foi, em vários aspectos, turbulenta devido à sua declarada apreciação aos moldes acadêmicos e repúdio ao Modernismo.

Teixeira foi um intenso defensor dos moldes de produção acadêmica, vendo no desenho e na técnica artística as bases para qualquer arte de valor. “A técnica é de suma importância", diz ele a Amarante (1951a: 33), "não se pode [...] produzir boa pintura, sem bom dezenho [sic] e colorido porque 
ela é absolutamente indispensável". Nessa lógica, os modernistas para ele "são uns fracassados [...] não sabem desenhar o perfil de uma batata" (AMARANTE, 1951a: 33). Teixeira retoma a denúncia do Modernismo como aberração e teratologia (monstruosa e cheia de más formações) e, nesse sentido, apontava a decadência da arte brasileira como inevitável.

As entrevistas de Newton Amarante com outros artistas não divergem muito do dito por Teixeira. Jornalista do Jornal do Brasil, em 1951 Amarante inicia uma coluna semanal dedicada a entrevistar os "maiores e mais notáveis artistas brasileiros" (AMARANTE, 1951a: 33). ${ }^{7}$ Do ponto de vista do autor, seriam estes os que receberam mais honrarias e prêmios na academia. Não por acaso, os entrevistados escolhidos tinham certa tendência a enxergar o Modernismo como um processo de decadência da arte brasileira, tal como Teixeira. As perguntas feitas por ele tinham claro objetivo de demonstrar esse ponto. Amarante fazia no geral uma série de perguntas, eram elas: "como considera a arte?", "o que pensa do modernismo?", “o que pensa da arte brasileira?" e se o entrevistado "percebia decadência ou evolução na arte brasileira". No início das colunas, no entanto, é possível perceber a opinião do próprio autor: a arte brasileira se perdeu depois dos grandes mestres como Pedro Américo, Victor

\footnotetext{
${ }^{7}$ De produção semanal, as colunas tiveram como entrevistados: o diretor do Museu Nacional de Belas Artes, Oswaldo Teixeira (conhecido publicamente por sua oposição ao modernismo), Manoel Constantino e Walter Feder. Outras colunas de Amarante tratavam de "Um período da vida de Oswaldo Teixeira" (claramente alvo de favoritismo do jornalista), "Arte e política" (em que tece uma relação clara entre desorganização social e um hipotético projeto político modernista) e "A finalidade educativa das artes" (no qual o autor frisa sua conclusão sobre a situação do movimento artístico brasileiro, ou seja, seu estado contínuo de decadência).
} 
Meirelles, Almeida Júnior, Batista da Costa e Rodolpho Amoedo. Os modernistas nada mais seriam do que uma "legião de incapazes" cujo desequilíbrio mental produzia monstros artísticos que sequer mereciam a alcunha de "subarte" (AMARANTE, 1951a: 33).

Para o jornalista, suas contínuas visitas aos Salões Nacionais apenas serviam para comprovar o "congelamento da nossa evolução espiritual e cultural", dando a impressão de que vivia-se "fora da civilização ocidental ou em meio a uma civilização de Incas ou Astecas" (1951b: 33), associando claramente a arte modernista ao "primitivismo". Suas apreciações não param por aí. A arte moderna seria "ingenuidade infantil", as deformações estéticas promovidas por ela indicavam a necessidade de que seus autores retornassem aos princípios fundamentais da educação artística, tal era o “espetáculo constrangedor" que formava (1951b: 33).

Walter Feder, em entrevista a Teixeira, em 1951, expressa: “depois do impressionismo o que se apresentar será apenas a destruição da beleza criada por Deus, Artista supremo do Universo" (AMARANTE, 1951c: 33). $\mathrm{O}$ jornalista esperava com suas colunas que, ao estudar-se a história da arte brasileira do seu período, ele e os membros de sua geração não seriam colocados "entre os que iniciaram a decadência da civilização e da cultura em nosso país" (1951b: 33). Amarante certamente não esperava que a narrativa modernista solaparia quase que completamente sua geração da história da arte, eles seriam vistos simplesmente como os "academicistas" que se recusavam a aceitar o avanço da arte nacional. 
A narrativa do Modernismo como uma ferramenta de proliferação do comunismo pode ser vista claramente na crítica de Newton Amarante. Assim, a arte moderna teria surgido como forma de facilitar a "implantação de ideologias que não podem florescer na sociedade nem frutificar sem o adubo da desorganização" (AMARANTE, 1951b: 33), isto significa: o comunismo. O jornalista escreve o seguinte:

A maioria dos brasileiros não conhece a maneira de agir dos petroleiros que procuram, com a confusão e a desorganização, impôr-se como única força política organizada: eles procuram atingir e arruinar as duas colunas mestras da civilização ocidental: a economia e a cultura. A primeira, conseguem com o fomento às greves despertando reivindicações, estimulando a luta de classes e, a segunda, destruindo conceitos, procurando açular estudantes e, principalmente, no meio artístico promovem, por meio de seus adeptos $\mathrm{o}$ desmoronamento das normas estéticas e tradicionais (AMARANTE, 1951b: 33, grifos meus).

“Os petroleiros" faz referência, muito provavelmente, aos movimentos nacionais que reivindicavam o monopólio estatal do petróleo e a organização do sindicalismo petroleiro. Assim, Amarante associa os movimentos grevistas do período a uma tentativa de desorganização social, econômica e cultural. Essa "revolução desvairada", para reutilizar o termo usado por Guanabarino em 1921, promove "o desmoronamento das normas estéticas e tradicionais" na arte (AMARANTE, 1951b: 33). Segundo a lógica destes dois críticos, a associação entre o movimento dos trabalhadores à decadência artística se deve à propagação de desordem 
social: o vácuo social, político, econômico e cultural criado pelo Modernismo era um projeto de divulgação do comunismo. Os críticos percebiam o viés político que o movimento modernista poderia tomar ao ilustrar as questões cotidianas dos trabalhadores brasileiros. Em 1934, o Realismo Socialista propunha exatamente esse viés: as artes plásticas e a literatura deviam divulgar a ideologia socialista aos trabalhadores através da representação do cotidiano do povo (COELHO, 2017: 590). Não pretende-se analisar quais modernistas brasileiros se apropriaram do realismo socialista, apenas demonstrar que alguns dos críticos aqui trabalhados acusavam o movimento modernista de promover a desorganização social e cultural, de modo a divulgar o "fomento a greve" e estimular a luta de classes para causar o "desmoronamento" da tradição e norma estética na arte.

Existe uma característica em comum que parece não abandonar aos críticos da arte moderna: a crença de que as artes modernistas nada mais são do que acontecimentos efêmeros. Lobato, em 1917, dizia que esse movimento nada mais era do que "[...] estrelas cadentes, brilham um instante, as mais das vezes com a luz de escândalo, e somem-se logo nas trevas do esquecimento". Guanabarino afirmava, em 1921, que "isso que por aí anda é uma questão de moda, e toda moda é transitória" (apud CAIRES, 2017: 92). No vigésimo aniversário da Semana em 1942, Bracet relata em entrevista que "todas essas coisas, felizmente, não chegaram a criar raízes e já morreram" (GOMES, 1942: 1). Newton Amarante não expressa diretamente essa ideia, mas aponta, claramente, a esperança de 
Cadernos de Clio, Curitiba, v. 12, $n^{\circ} .1,2021$

que os artistas formem muralhas "para represar e manter em nível elevado o conceito artístico que conseguimos desfrutar com as obras de Pedro Américo, Vítor Meirelles, Almeida Júnior” e outros (1951b).

\section{Considerações finais}

Ao contrário do que se está acostumado a ver, as tensões críticas no campo artístico em São Paulo e no Rio de Janeiro duram muito mais tempo e são muito mais complexas do que deixa ver a narrativa modernista. Já em finais dos anos 1890, artistas da AIBA discutiam modos de atualizar a arte brasileira dentro das tendências modernas divulgadas pela Europa. Nas duas primeiras décadas do século $\mathrm{XX}$, os modernistas fazem esse mesmo processo, mas são vistos com maus olhos por alguns dos artistas que antes defendiam a modernização artística. $\mathrm{O}$ que se discute, na realidade, como pode-se ver nas críticas aqui apresentadas é a tendência de defesa do desenho e da forma como bases da arte. Para esses críticos, como expressão da individualidade dos artistas, a arte deve ser dotada de liberdade de expressão, contudo essa liberdade está intimamente atrelada à manutenção da forma e do desenho. Ou seja, uma arte digna de elogios seria, na visão desses críticos, estruturada a partir do estudo mais real possível de formas da natureza. E, a partir daí, o Modernismo é criticado como degeneração, ele não só desvirtuou totalmente a estética artística como, devido a isso, iniciou um processo de decadência da arte brasileira.

Seja na crítica de Lobato em 1917; de Guanabarino na década de 1920; de Bracet, na de 1940 ou de Newton Amarante em 1950, existem 
conceitos que se repetem. Os modernistas são continuamente apresentados como charlatões que tentam enganar o público com sua falta de técnica artística (assim associados a uma produção infantil), comunistas que pretendem por meio das artes desorganizar a sociedade e propagar suas ideias, frutos do "excesso de civilização" que levaria à degeneração da cultura e loucos que fazem arte semelhante à dos hospícios. Essas narrativas não se reduzem à polarização academicismo-modernismo, ainda que esse aspecto faça parte de suas críticas. Os chamados "velhinhos" da Academia estavam adentrando na modernidade segundo seus termos e adotavam o uso de ideias degeneracionistas, cientificistas e evolucionistas para opor-se àquilo que acreditavam danificar a arte brasileira, não torná-la moderna.

Enquanto a crítica de Monteiro Lobato é uma das mais pontuais aqui apresentadas, as de Oscar Guanabarino perpassam quase 40 anos, indo desde as críticas ao imobilismo artístico da AIBA até a denúncia do Modernismo como "loucura epidêmica".

Bracet, Teixeira e Amarante, assim como Guanabarino, produziram crítica artística de forma mais organizada. Enquanto podemos perceber em Bracet uma recusa ao Modernismo por suas falas em entrevistas e pelo acontecido no salão de 1942, Teixeira era muito mais enfático. Ele nomeava diretamente quem criticava, ou seja, os modernistas. Muito provavelmente esse seja o motivo pelo qual sua figura, e não a de Bracet, está sempre atrelada à perseguição do Modernismo. Como diretores da ENBA e do Museu Nacional de Belas Artes, Bracet e Teixeira, 
respectivamente, agiram de forma mais direta na proibição da presença de obras modernistas em exposições. Já a coluna de Amarante, na década de 1950, comprova que tensões críticas acompanharam todo o processo de afirmação do Modernismo no Brasil. Ou seja, esse quadro não se restringiu aos ataques da Semana de Arte Moderna em 1922.

Amarante, contudo, está longe de refletir o senso comum da época, como reflete Souza (apud CAIRES, 2019), sobre as produções de críticas artísticas em periódicos. Com certeza Amarante não era o único nessa década que criticava o Modernismo, ainda mais em um período de intensos conflitos políticos que se davam em razão da Guerra Fria. Contudo, sua coluna reflete, em realidade, diferentes ecos de sua própria opinião. O autor fez uma seleção clara de artistas que pensavam como ele: viam o comunismo se permeando na arte e enxergavam um quadro de decadência constante para a arte brasileira, para além de sonharem incessantemente com Rodolpho Amoedo, Pedro Américo, Victor Meirelles, Almeida Júnior, Batista da Costa e outros considerados por eles como os grandes pintores da arte brasileira.

$\mathrm{Na}$ década de 1950, em plena Guerra Fria, as tensões críticas se voltam ao uso de termos políticos do período. Se por um lado os críticos da arte moderna associavam os modernistas aos comunistas que propagaram a degeneração da arte, à involução da cultura humana - inclusive é possível encontrar associações da arte de vanguarda com o bolchevismo russo e o judaísmo, por outro, os defensores do Modernismo se utilizavam de retórica semelhante: não apenas conectavam seus carrascos ao governo 
nazista alemão (eram eles membros do "terceiro reich"), como também à bastilha francesa, sendo, então, os modernistas os revolucionários responsáveis por derrubar os opressores e ditadores das artes.

\section{Referências}

AMARANTE, Newton. "Artes Plásticas: entrevista com o professor Oswaldo Teixeira". Jornal do Brasil. Rio de Janeiro, ed. 74, 1-2 abril 1951a, p. 33. Disponível em: https://bit.ly/3q8cvtu. Acesso em: 04 mar. 2021.

. O "Salão de Belas Artes de 1951". Jornal do

Brasil. Rio de Janeiro, ed. 209, 9-10 set. 1951b , p. 33. Disponível em: https://bit.ly/3sRcoo2. Acesso em: 04 mar. 2021.

"Os pintores da nova geração: entrevista com o pintor Walter Feder". Jornal do Brasil. Rio de Janeiro, ed. 86, 15-16 abril 1951c, p. 33. Disponível em: https://bit.ly/3qfGSOB. Acesso em: 04 mar. 2021.

CAIRES, Daniel Rincon. Oscar Guanabarino: de moderno a "passadista". 19\&20, Rio de Janeiro, v. 12, n. 1, jan./jun. 2017.

- Lasar Segall e a perseguição ao Modernismo: Arte Degenerada na Alemanha e no Brasil. 279f. 2019. Dissertação (mestrado) - Universidade de São Paulo, São Paulo, 2019.

COELHO, Tiago da Silva. "O realismo socialista na pintura brasileira: convergências e divergências da historiografia nacional". In: ENCONTRO DE HISTÓRIA DA ARTE, XII, 2017, Campinas. Anais eletrônicos, 2017, p. 589-593.

CHIARELli, Tadeu. "De Anita à Academia”. Novos Estudos. São Paulo, v. 28, n.3, p. 113-132. nov./2010.

COSTA, João Angyone. A inquietação das abelhas - O que dizem nossos 
pintores, esculptores, architectos e gravadores, sobre as artes plásticas no Brasil. Rio de Janeiro: Pimenta e Mello \& Cia, p. 148-154, 1927.

FABRIS, Annatereza. Figuras do moderno possível. In: SCHARTZ, Jorge (org.) Da Antropologia a Brasília: 1920-1950. São Paulo: FAAP, 9. 41-51, 2003.

GOMES, Tapajós. Augusto Bracet: O artista que foge do feio e do trapo. Correio da Manhã, Rio de Janeiro, ed. 14488, 25 jan. 1942, p. 1 e 8, Disponível em: https://bit.ly/3r9Zz7K. Acesso em: 04 mar. 2021.

LOBATO, Monteiro. Paranóia ou mistificação. O Estado de São Paulo. São Paulo, 20 dez. 1917. Disponível em: https://bit.ly/3e6oMfH. Acesso em: 04 mar. 2021.

MAURÍCIO, Jayme. "Modernismo versus Oswaldo Teixeira". Correio da Manhã. Rio de Janeiro, ed. 24641, 12-13, jan. 1973, p. 10. Disponível em: https://bit.ly/3uQ2dSp. Acesso em: 04 mar. 2021.

SILVEIRA, Joel. "Os modernos expulsos da Escola de Belas Artes". Diretrizes: Política, Economia, Cultura. Rio de Janeiro, ed. 128, 10 dez. 1942, p.12-13. Disponível em: https://bit.ly/3e2rH90. Acesso em: 04 mar. 2021.

SIMIONI, A. P.; STUMPF, L. O Moderno antes do Modernismo: paradoxos da pintura brasileira no nascimento da República. Teresa revista de Literatura Brasileira, São Paulo, n. 14, p. 111-129, 2014.

TRIUNFO da Arte Moderna. Sombra. Rio de Janeiro, ed. 14, 1943, p. 24-25. Disponível em: https://bit.ly/2OmkNAI.

Recebido em: 05/03/2021 Aceito em: 20/09/2021 